\title{
Review: deformation and optimisation crashworthiness method for foam filled structures
}

\author{
Fauzan Djamaluddin ${ }^{a}$ \\ a Departement of Mechanical Engineering, Faculty of Engineering Hasanuddin University, Gowa, South Sulawesi, Indonesia. E-mail: \\ fauzanman_77@yahoo.com \\ *Corresponding author
}

https://doi.org/10.1590/1679-78255702

\begin{abstract}
In this paper, we give overview of deformation modes for the uniform foam filled thin-walled structure such as circular tubes, square tubes, rectangular tubes, tapered tubes, hat tubes and cone tubes. Foam material is used as a reinforcing material on a thin wall tube which has potential as being a good energy absorber. This is evident from many of the studies undertaken on the crashworthiness performance and energy ab-sorption of the thin wall tube. Also, this paper presents a review of the current state of the art in computa-tional optimization methods applied to foam filled structures, offering a clear vision of the latest research advances in this field.
\end{abstract}

\section{Keywords}

tube, foam, optimization, metamodel

\section{INTRODUCTION}

Thin-walled tube structures include circular tubes, square tubes, rectangular tubes, tapered tubes, cap tubes and cone tubes. In order to improve crashworthiness performance without adding weight to the structure, foam filled thinwalled tubes can be utilised. Studies on foam materials, the mechanical properties of aluminium foam and the effect of interactions between the foam and the tube wall are described in this paper. Also, based on the impact velocity, the tubes are divided into conditions under static and dynamic quasi-loading. As viewed from the loading angle, each the tube is divided by the axial and angular loading conditions. In addition, according to the structural cross-sectional configuration of the structure, it is divided into single tubes and double tubes. Indeed, many previous studies the crashwothiness analysis on structures using experimental, numerical and theoretical methods.

Energy absorption is a system that converts all or part of the kinetic energy to another form of energy. In this case, the energy is either reversed, such as pressure energy in compressible fluid and elastic strain energy in solids, or the energy cannot be changed, such as plastic deformation energy (Alghamdi 2001). Additionally, the energy-absorbing structure is destroyed in a predictable collapse if the energy level is not controlled in a real system. In this case, the destructive structure acts as energy absorption as a tool for converting the kinetic energy into other types of energy, which reduces the peak force of the damage delivered to the structure to be protected. The energy-absorbing performance of the tubular structure can be categorised in a variety of ways in order to accommodate the widespread application (Ahmad and Thambiratnam 2009).

Various reference sources have been studied for different energy absorption applications. For example, Fang et al. (2015) investigated the characterisation of energy absorption from an automobile crash box at a low-velocity impact using the finite element method. They also investigated the design optimisation for different cross sections and tubular wall thicknesses. The other component that has been investigated included the design and analysis of the front bumper of the automotive vehicle to improve the crashworthiness design involving a low-velocity impact. These components 
have been investigated by Marzbanrad et al. (2009). Notwithstanding, B-pillar optimum designs have also been proposed using Tailor Welded Blank (TWB) as explored by Pan et al. (2010).

To develop an energy absorption system, it is necessary to investigate the absorption of existing energy to suit the use of this system or whether the system should be modified or redesigned. For example, in selecting the type of absorption such as in a bumper system, the main feature to emphasise is the energy absorption capacity of the system. Furthermore, other aspects, such as the absorption of energy, the complexity and availability of the energy-absorbing system need to be considered given the materials are still limited to materials such as composite materials.

The metamodel method or surrogate model (Gao et al., 2016a) forms part of the design optimisation concept for modern engineering structures which combines experimental design and simulation to reduce the amount of data. The metamodel technique is commonly chosen based on time and accuracy of the calculation. Some metamodel techniques are described by Yin et al. (2014a) and Fang et al. (2014) for crashworthiness design optimisation. However, in the majority of cases, the crashworthiness of vehicles is viewed as a multi-objective problem requiring the concurrent calculation of all functions in the system to determine the optimum value. The objective function for the crashworthiness structure is the maximum energy absorption capacity for crashworthiness and the minimum weight of the vehicle structure. This paper reviews deformation modes of foam-thin wall structure under different loading, optimization algorithm, metamodel development and crashworthiness design optimization method for foam filled thin wall structure.

\section{CRASHWORTHINESS PERFORMANCE INDICATORS}

To assess the energy of structural absorption, it is important to understand about crashworthiness performance indica-tors. Related parameters such as energy absorption (EA), Spesific Energy Absorption (SEA) and Peak Crushing Force (PCF) can effectively be employed to assess the crashworthiness structure. Energy absorption can be calculated as the area under the displacement energy curve, as illustrated in Figure 1 (Tarlochan et al. 2013).

$$
E A=\int_{0}^{\delta} F(x) d \delta
$$

Where EA is the energy absorption of the structure and $F(x)$ is the instantaneous crushing force with displacement function. Specific energy absorption can be expressed in the equation as given below (Kim 2002);

$$
S E A=\frac{E A}{m_{\text {total }}}
$$

Where SEA is specific energy absorption, EA is the energy absorption of the structure and $m_{\text {total }}$ is the mass of the entire structure. In this case, a high value indicates that the material contains high energy absorption capability. Moreover, this shows that the higher the value of SEA, the better the absorption energy of the material. Other indicators related to energy absorption capabilities include Crushing Force Efficiency (CFE), which can be expressed as given below (Zarei and Kroger 2007);

$$
C F E=\frac{P C F}{M C F} \times 100 \%
$$

Where CFE is the energy efficiency of destruction, PCF is the peak of crushing energy during the collision process, and MCF is the average destruction energy expressed as the total energy absorption divided by the displacement. MCF value is the response parameter for energy absorption capability which can be calculated as shown in the expression below;

$$
M C F=\frac{E A}{\delta}
$$




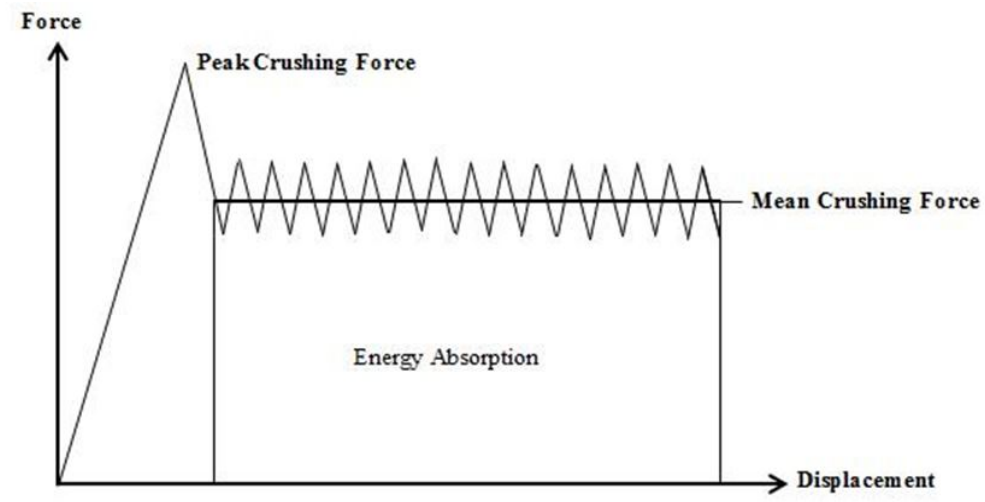

Figure 1. Energy versus displacement for crashworthiness performance. Source: Tarlochan et al. (2013).

\section{FOAM FILLED THIN WALL STRUCTURES}

Some references were carried out in this study about the application of the foam filled thin-walled tubular structure. This application is used as a reinforcing material on a thin wall tube which has potential as being a good energy absorber. This is evident from many of the studies undertaken on the destruction and energy absorption of the thin wall tube structure in axial loading. For foam filled square tubes, quasi-static and dynamic tests were carried out by Hanssen et al. (2000) to investigate the behaviour of aluminium extrusion with foam. Also, to further rein-force the foundation of the experiment, it is important to develop a design formula in order to predict the average crushing energy of both quasistatic and dynamic conditions. Accordingly, this design formula is developed through existing theories of quasi-static destruction for non-foam aluminium extrusion. Here, a comprehensive experiment and numerical study regarding the behaviour of the collapsible foam containing aluminium through axial loading compres-sion was conducted by Santosa et al. (2000). The results of this study suggest that the prediction of destruction and creep formation can be found based on the experimental results. Further, the results obtained were shown to be more than $8 \%$ compared to the experimental values for various data such as geometric shapes, materials and foam strength. Impact tests on empty and foam-filled square tubes were also carried out by Zarei and Kroger (2008).

The optimum value of the square tube contained the same absorbing foam as the empty tubes, but the square tube containing the foam had a weight $20 \%$ lower than the empty square tube. The axial compression test was also performed for emp-ty columns containing foam with rectangular and square cross sections to determine the maximum compression force by Abedi et al. (2012). Here, they found that the theoretical results with experimental measurements showed good equations; moreover, resulting in the accuracy of the presented theory, and the prediction of the theoretical error being less than $10 \%$. Figure 2 illustrates the deformation modes for the foam filled square tube under the axial im-pact referred to from several sources.

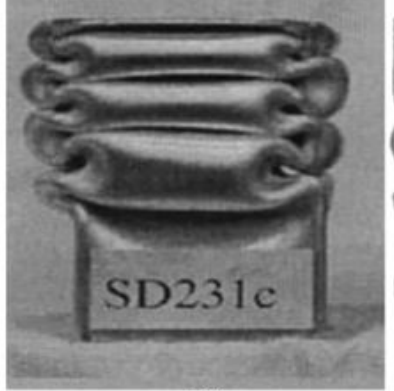

(a)

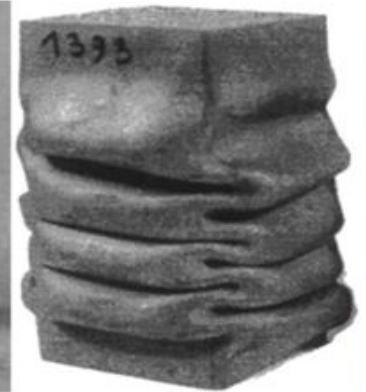

(b)

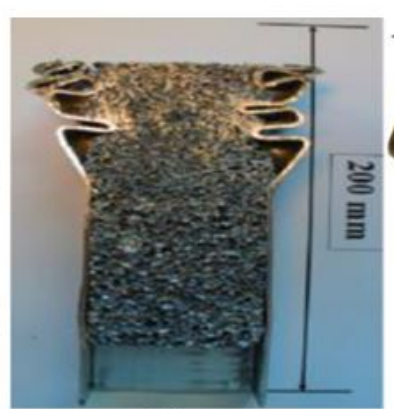

(c)

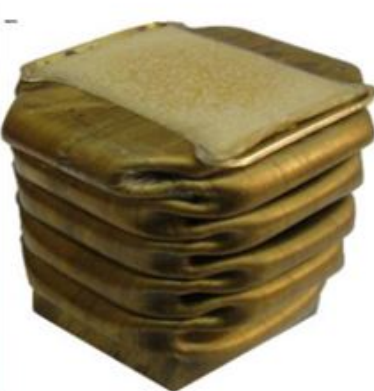

(d)

Figure 2. Deformation modes of foam filled square tubes under axial loading (a) Hanssen et al. (2000), (b) Santosa et al. (2000), (c) Zarei and Kroger (2008) and (d) Abedi et al. (2012).

For circular tubes filled with foam, experiments and forecasts of the absorption of circular tube filled energy have been conducted. Although foam-filled structures provide high energy absorption, the results compared to empty tubes and foam alone (without tubes), showed that it is not necessarily effective to increase specific energy absorption with 
dif-ferent tube wall thicknesses. Therefore, the selection of tubular and foam combinations is extremely important by considering the magnitude of foam-filled reinforcement and tube filler loading (Kavi et al. 2006). The effect of filler foam is more pronounced for the average destruction of the crushing force peak, where it is important to use a full foam tube in the accident component (Borvik et al., 2003). The reinforcement effect of tube filler foam has also been studied using aluminium tubes containing polymer foam types in two deformation modes. In this case, the foam filling made changes to the deformation modes for aluminium tubes in forming diamond structures to concertina struc-tures due to the effect of the tubular wall thickness (Toksoy and Guden 2005). Yan et al. (2007) investigated the energy absorption capability of the composite structure caused by plastic deformation during the crushing process by compar-ing the foam filled tube structure. The results showed that the energy absorption of foam-filled tubular structures was dominant as compared to those having without foam. Notably, the effects of different energy absorption of friction and structural geometry parameters were also studied. In another study, Ghamarian et al. (2011) examined the mechanism of collapse and the energy absorption capacity during the axial compression test from the tip of a thin-walled circular tube between being hollow or plastered with foam. Figure 3 shows a circular tube-shaped deformation mode through axial loading based on several studies.

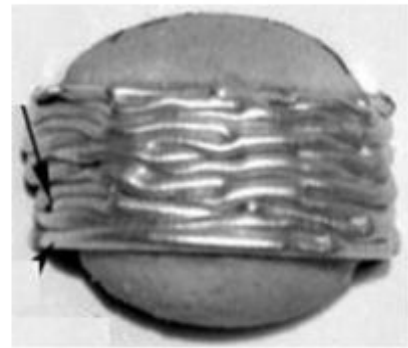

(a)

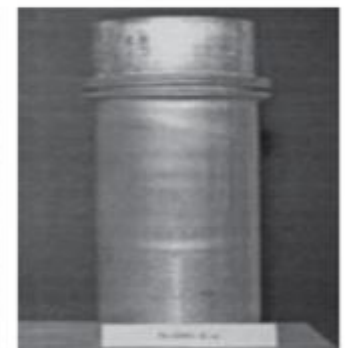

(b)

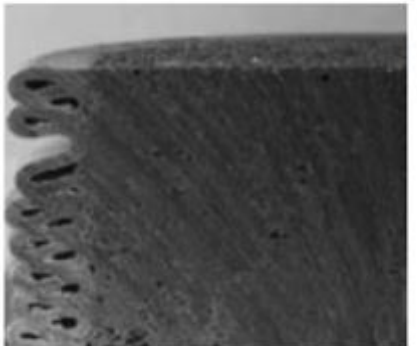

(c)

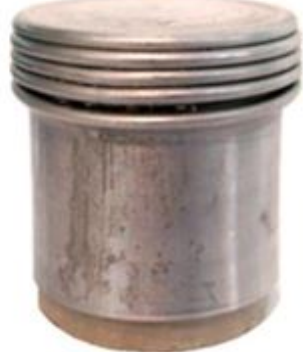

(d)

Figure 3. Deformation modes of foam filled circular tubes under axial loading: (a) Borvik et al. (2003), (b) Toksoy and Guden (2005), (c) Yan et al. (2007), (d) Ghamarian et al. (2011).

For the foaming foam parts, a theoretical analysis was carried out to predict the crushing and interactive effects of the foam cap. The SEA value for foaming foam caps was found to be higher compared to a foam-filled cap having a similar thickness of $3 \mathrm{~mm}$ (Wang et al. 2007). Also, the finite element analysis and theoretical analysis showed an in-crease in energy absorption for both the cap tubes when filled with foam. This leads to the contribution of the interac-tive effects between the cap tube wall and the foam filler (Song et al. 2005). In a separate study, Altenhof et al. (2002) conducted experiments and numerical trials of soft-filled soft steel tube tubes under axial compression conditions and provided information on their energy absorption capacity. Similarly, Allahbakhsh and Saetni (2011) ex-plored the design of crashworthiness filled columns of foam and empty columns made of soft steel, accompanied by spot-welding. In their study, they obtained the optimum value for a small empty state compared to a foam-filled cap. Figure 4 displays the deformation mode of the cap containing foam under the axial loading.

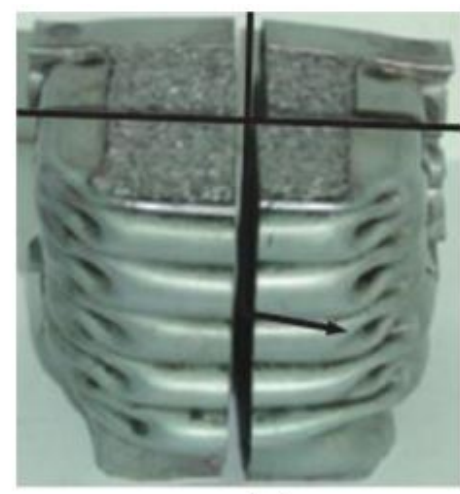

(a)

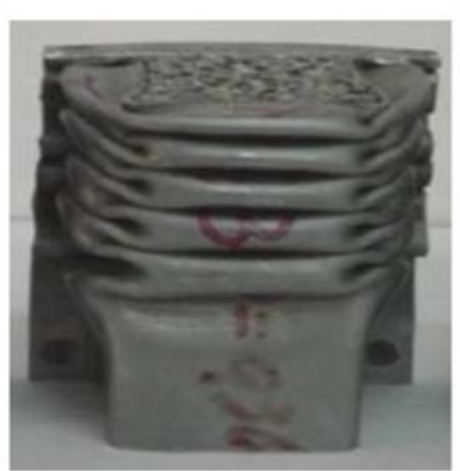

(b)

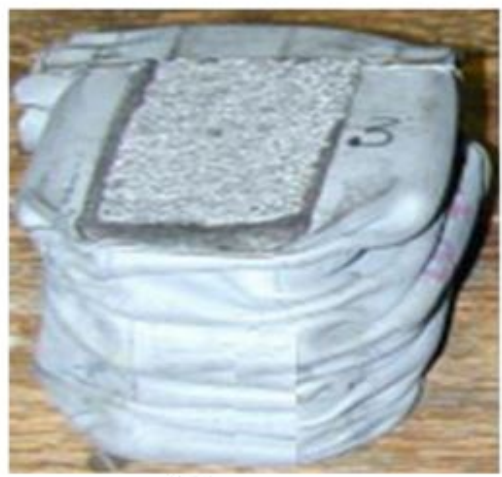

(c)

Figure 4. Deformation modes of foam filled hat tubes under axial loading; (a) Wang et al. (2007) (b) Song et al. (2005) (c) Altenhof, et al. (2002). 
Foam filled rectangular tubes were also studied by Mirfendereski et al. (2008). In this study, they deter-mined the disintegration behaviour of thin-walled tubes in the static and dynamic loading bands, as shown in Figure 5 . Experiments were performed employing parameters such as sloping sides, foam density and different boundary conditions. Additional features were also identified such as shape defects, displacement loads, length creases and spe-cific energy absorption. On the other hand, Nagel and Thambiratnam (2004) conducted a study to compare energy absorption reactions for straight tubes and rectangular tapered tubes under the axis of quasi-static and dynamic impact axes. The parameters used were wall thickness, tapered angle, impact mass and varying impact velocity. The results indicated that the dynamic response to the tapered tube reacted to the impact velocity and wall thickness compared to the taper angle parameter for low impact velocity.

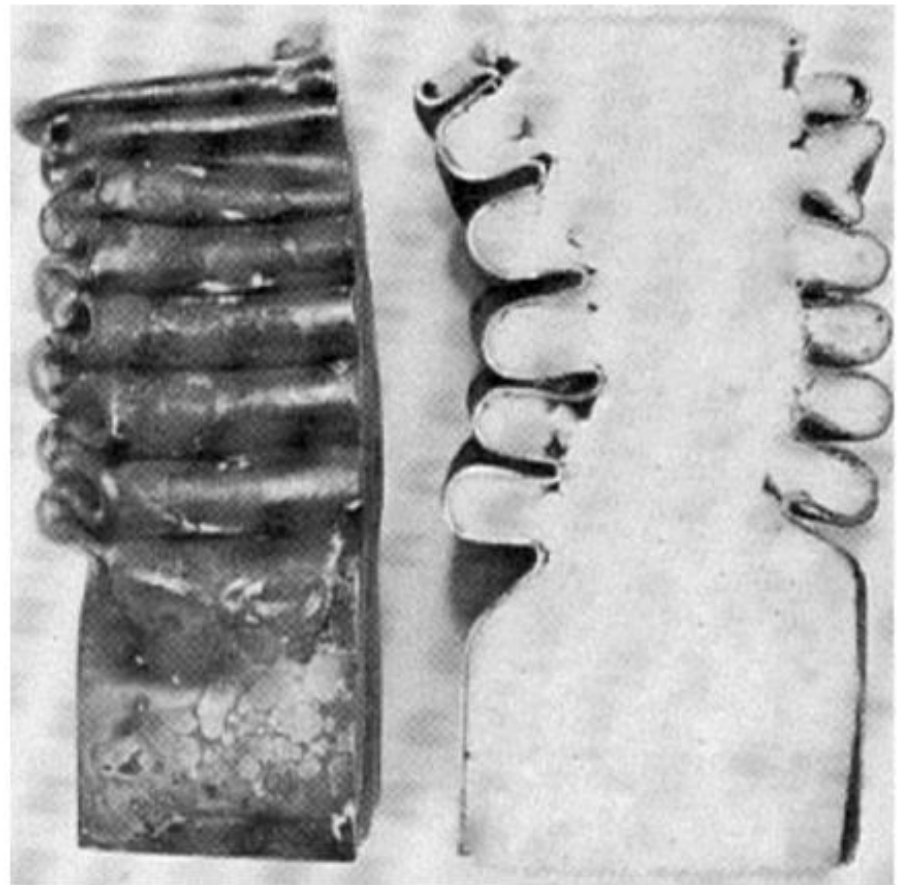

Figure 5. Deformation modes of foam filled tapered tubes under axial loading. Source: Mirfendereski et al. 2008

Ahmad and Thambiratnam (2009) examined the effect of foam fillers on cone tubes using dynamic responses and char-acteristics of energy absorption using finite element simulations. Here, the parameters varied, namely foam density, wall thickness, semi-apical angle, impact mass and impact rate. However, other work carried out by Ghamarian et al. (2011) found that the energy absorption capacity of foam-filled tubes was $18.4 \%$ higher compared to the effect of the combination of empty tubes and foam. Also, the aluminium cone that was used for the full implementa-tion of the foam experiment was higher than $10 \%$ of the energy absorption compared to the empty cone as described by Hou et al. (2013). Figure 6 displays the deformation modes of cone tube types that were used based on previous studies.

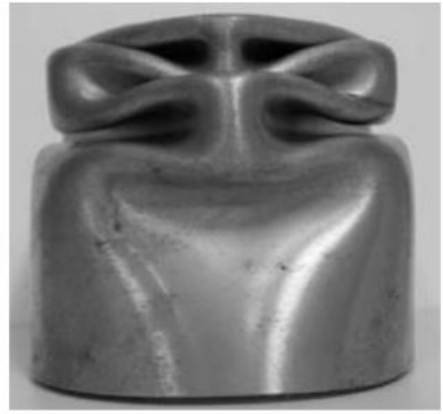

(a)

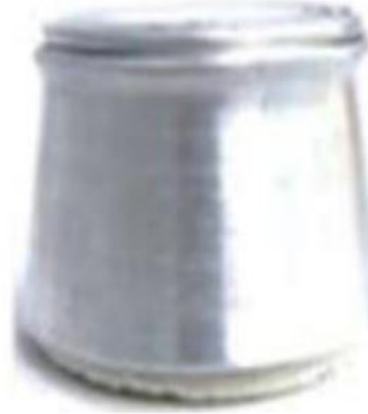

(b)

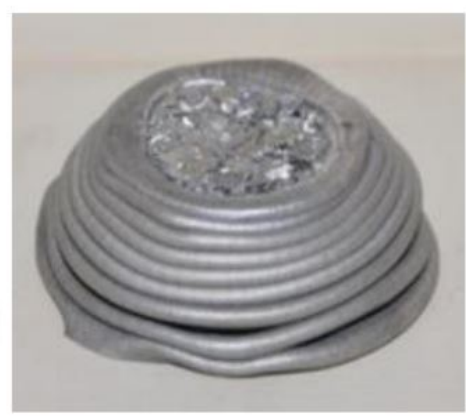

(c)

Figure 6: Deformation modes of foam filled cone tubes under axial loading; (a) Ahmad and Thambiratnam (2009),

(b) Ghamarian et al. (2011), Hou et al., (2013). 
Studies conducted on thin-walled tubes under oblique loads are shown in Figure 7. The analysis conducted by Han and Park (1999) relates to the behaviour for gentle square steel columns that were subjected to oblique loading. Here, the oblique loading affected the columns on rigid walls that were rejected without friction. Also, different angles were studied, in which the reactions are divided into three parts, namely broken axes, broken bends and transitional zones. An empirical angular expression is also given in this study. Further, this foam-filled structure was examined using a thinwalled aluminium extrusion subjected to oblique loading. The type of oblique loading such as the reaction to the square structure of aluminium extrusion (Reyes et al. 2002) has been investigated on empty tube and foam-filled square tubes (Reyes et al. 2003) and aluminium circular tubes (Borvik et al. 2003) using quasi-static experiments. Whereas for other structures, Ahmad et al. (2010) explored the ad-vantages of using foam-cone tubes under oblique loading. Here, cone foam filled were found to have effective energy absorption structures given they were able to withstand the oblique load impact effectively. The cone tubes were able to effectively withstand the oblique load impacts and even the minimum reduction in energy absorption due to the increased load angle. Figure 7 illustrates a foam-filled structure subjected to oblique loading.
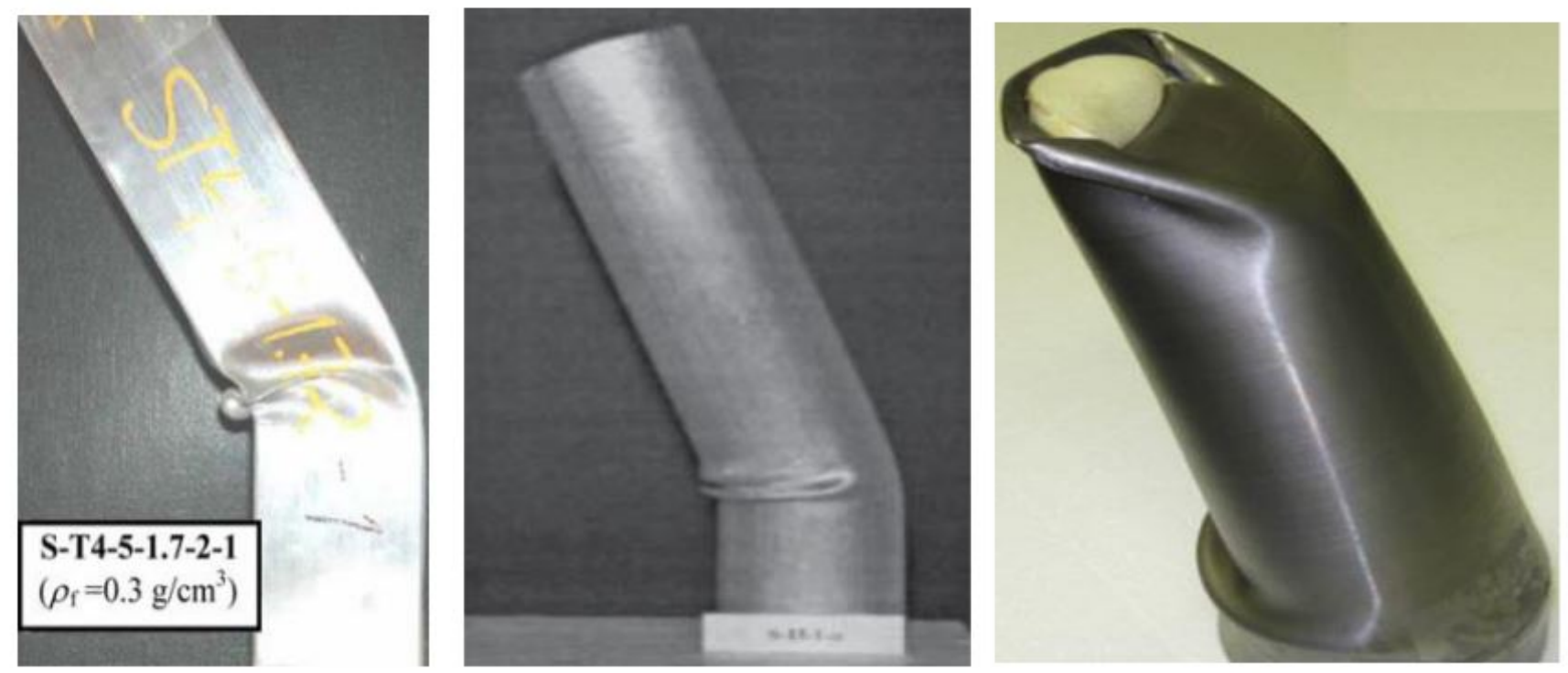

Figure 7: Foam filled structures under oblique loading; (a) Square tube by Reyes, Langseth and Hopperstad (2003), (b) Circular tube by Borvik et al., (2003), (c) Cone tube by Ahmad et al. (2010).

The studies show that not only do foam fillers have the ability to absorb energy with plastic deformation, but the combination of tubes and foam fillers play an important role by changing the mode of failure to a more effective mode. The study conducted by Seitzberger and Willminger (2001) investigated the effects of double foam filler and tubes for the destructive behaviour of axial-compressed tubes in which the double tube arrangement tubes was described as a more effective crashworthiness element compared to a single tube. Yuen et al. (2008) used a double-cell profile arrangement in which two similar tubes were cross-sectioned and placed in the same centre. Notwithstanding, empty tubes and aluminium foams have also been studied where comparisons of energy absorption were adopted. Circular foam-filled double tubes have also been used in experimental investigations and numerical methods in order to devel-op a topological structure with axial loading conditions (Guo and Yu 2010) and three-point flexibility (Guo and Yu 2011) and oblique loading (Djamaluddin et al. 2015a, 2016). Figure 8 shows the filled foam on a double tube subjected to axial impact. 


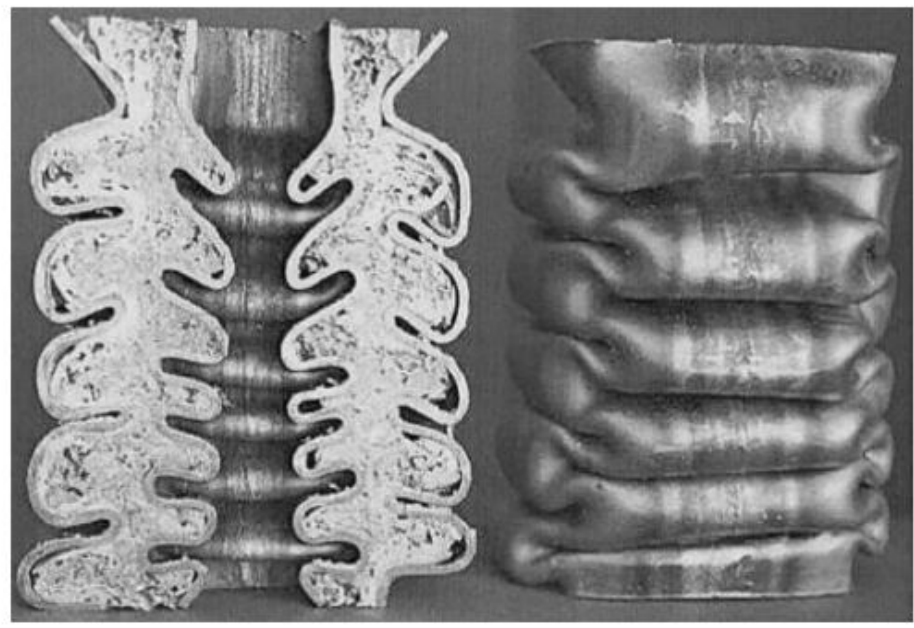

(a)

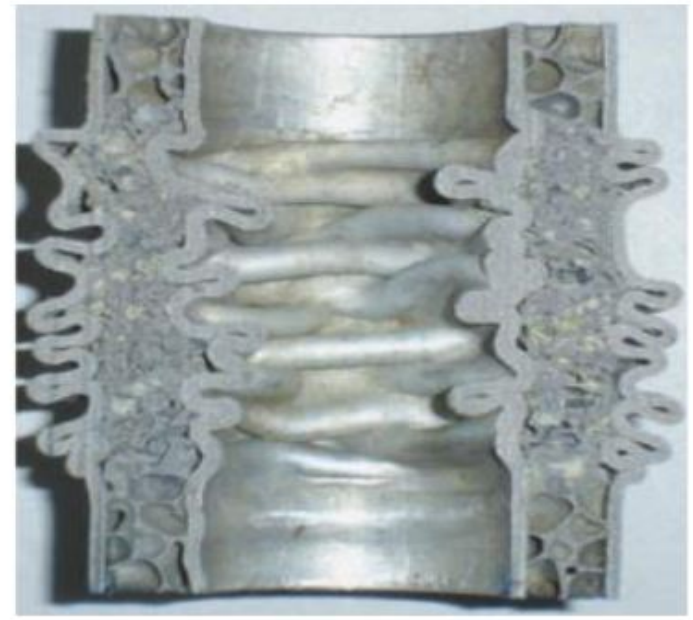

(b)

Figure 8: Double tube under axial loading; (a) square tube by Seitzberger and Willminger (2001), (b) circular tube by Guo and Yu (2010).

\section{OPTIMISATION DESIGN FOR CRASHWORTHINESS}

The manufacturing and automotive industries employ Computer-Aided Engineering (CAE) to design crashworthiness in order to reduce the cycle time of the design phase (Nagel and Thambiratnam 2006). Importantly, numerical optimisation techniques provided a systematic approach in achieving the desired design objectives in a much shorter period. How-ever, crashworthiness numerical optimisation still faces difficulties, especially from a technical perspective. Direct op-timisation techniques that are gradient-based are viewed as conventional methods that require numerous functions and are not recommended. Also, the crashworthiness analysis method in this calculation requires significant costs be-cause limited time is needed in explaining that the finite element method is not linear (Ahmad and Thambiratnam 2009). Moreover, the crush function in the crashworthiness analysis is extremely complicated and irregular due to the touch-impedance algorithm being a finite element that is not linear. Accordingly, this problem affects the design parameters that rely on finite element mesh. Additionally, complex product design requires extensive review of the product re-sponse following external load, which can be achieved through physical experiments or computer simulation. However, this form of simulation can be challenging from a computer technology point of view. In the time required to optimise product performance, the requirements for the model are summarised using an efficient and detailed model. The summary of this model is called a replacement model and the replacement model for a detailed simulation model is called a metamodel. This term is used for optimisation based on simulation (Ryberg, 2013).

\subsection{Development of the Crashworthiness Optimisation Based Metamodel}

The metamodel is a mathematical method based on the input data set to produce the output of the simulation model, as shown in Figure 9. For example, a suitable metamodel type for estimation depends on the physics base where different data sets will form different metamodels. The Design of Experiment (DOE) is a process employed for designing design points in design areas such as the input settings for data sets (Fang et al., 2005). Metamodels are developed from sample data either collected from physical experiments or calculated from computer simulations using finite ele-ment analysis where the data is collected from the design space by specifying the design variable range. The custom space is according to the point, where each dot represents a combination of variables at different levels. The DOE is used to reduce the number of input data in metamodel development. Moreover, the DOE is a statistical technique used for information employing several simulations having different variables in order to understand the behavioural re-sponses (Yin et al., 2014b). D-Optimum was selected in this study as the DOE based on the reduction of variance in the development of the metamodel method (Gao et al., 2016b).

In order to reduce the calculation time, this metamodel technique has been used extensively for design optimisation. Metamodel techniques such as Polynomial Response Surface (PRS), Radial Basic Function (RBF), kriging, Support Vector Regression (SVR), Response Surface Method (RSM) and Artificial Neural Network (ANN). Different metamodels have different functions as well as having distinctive features according to the design engineer's requirements. 
Such as model, the approach, design space exploration, problem formulation and optimisation support (Wang et al. 2007) in Figure 9.

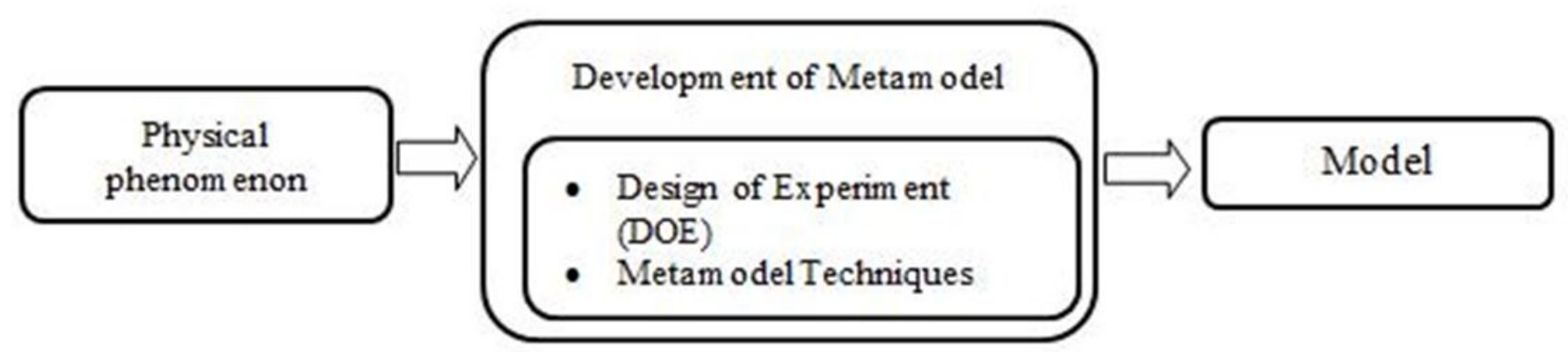

Figure 9: Metamodel development process for optimisation. Source: Acar et al. (2011).

\subsubsection{Polynomial Surface Reaction (PSR)}

The PRS metamodel technique is used in the development of the Taylor series (Ravindran et al. 2006). The Taylor series usually requires an infinite number of terms in order to obtain values for real functions. This polyno-mial surface reaction considers design optimisation problems which incorporate complex non-linear mechanics such as touch impact. For this approach, the approximation to the structural response is considered as a priority in the form of the polynomial functions as given below;

$$
\hat{\mathrm{y}}_{\mathrm{PRS}}(\mathrm{X})=\sum_{\mathrm{i}=1}^{\mathrm{k}} \mathrm{a}_{\mathrm{i}} \varphi_{\mathrm{i}}(\mathrm{X})
$$

Where $\hat{\mathbf{y}}_{\text {PRS }}(\mathrm{X})$ is Polynomial Surface Reaction, $k$ is polynomial function, $\mathrm{a}_{\mathrm{i}} \mathrm{s}$ coefficient of material and $\mathbf{X}$ is design variable vector.

Acar et al. (2011) used PRS for the optimisation of fibre tubes, suggesting that fibre tubes with curves have better crushing performance compared to non-curved tubes. It has also been found that the maximum CFE requires a large number of curves having a high radius, small thickness, and a tapered angle, while the maximum SEA requires a small number of curves having low radius, large thickness and small tip angles. Yin et al. (2014b) examined the optimum value for the thin-walled structure of the foam and multi-celled structure. This structure has gained much attention given its good energy absorption capacity using the metamodel, (i.e. PRS for accident simulation calculations with the finite element method). In addition, PRS is used to obtain results concerning the reactions on energy absorption and crushing force peak to assess the effect of longitudinal beam thickness, outer beam and middle beam (Xu et al. 2013).

\subsubsection{Kriging}

This method, derived from D.C. Krige's name, is used to build metamodels in engineering applications. The design and analysis of numerical experiments is a statistical framework for determining the approximation of kriging presented by

$\hat{y}_{\text {KRG }}(X)=g(X)+z(X)$

Where $\hat{\mathrm{y}}_{\mathrm{KRG}}(\mathrm{X})$ kriging metamodel, $\mathrm{g}(\mathrm{X}) \mathrm{s}$ polynomial function, $\mathrm{z}(\mathrm{X}) \mathrm{s}$ adalah stochastic process and $\mathrm{X} s$ design variable vector.

Zhang et al. (2012) employed the kriging metamodel technique to formulate the objective function for optimis-ing the crashworthiness of double-barrelled double tubes. The results showed that this tube configuration could be improved but could be an efficient energy absorber. The application of the kriging models has also been used to obtain the optimum value of dynamic reactions and the absorption of energy from a thin-walled foam conical tube under an oblique impact loading condition. The crust worthiness criteria of SEA and CFE showed that the foam-containing cone tubes had better impact performance compared to empty cob tubes under oblique impact bursts (Zhang et al., 2014). 
Yin et al. (2014b) also used kriging and other metamodel techniques to select the best metamodel for optimisation using the average root error (RMSE).

\subsubsection{Support Vector Regression (SVR)}

This method is capable of solving non-linear problems using kernel functions and succeeds on multiple domains (Raja-sekaran et al. 2008). The main aim of the SRV method is to search for another regression method to find the

$\hat{\mathrm{y}}_{\text {SVR }}(\mathrm{X})$ unction which accurately predicts the output at any value X. Generally, SVR provides the following regretting functions (Gunn 1998);

$\hat{\mathrm{y}}_{\mathrm{SVR}}(\mathrm{X})=\mathrm{W} \cdot \mathrm{k}(\mathrm{X})+\mathrm{b}$

Where, $\hat{\mathrm{y}}_{\mathrm{SVR}}(\mathrm{X}) \mathrm{s}$ the support vector regression function, $\mathrm{W}$ is weighting factor, $b$ is constant, $\mathrm{k}(\mathrm{X})$ is a non linear mapping function.

Zhu et al. (2012) used SVR for crashworthiness vehicle designs to enhance the destructive force of the roof and front end of the vehicle subject to frontal crashes. SVR is also used as an alternative to non-linear violation problems and is one of the successful alternatives to optimising metamodel designs. For instance, Pan et al. (2010) examined the B-pillar optimum design by suggesting the use of empty welding structures in order to reduce the weight under the roof constraints of vehicles using SVR as a metamodel method. Moreover, it showed that the predicted re-sults corresponded to the results of the simulation on the optimum solution with B-pillar weight reduction, reaching $27.64 \%$. Similarly, Zhu et al. (2012) compared SVR with other metamodel techniques for crashworthiness performance. The study aimed to test SVR and provide more suitable metamodel techniques in relation to automotive structures.

\subsubsection{Radial Basic Function (RBF)}

RBF is used for the adjustment of irregular topographic contours for geographic data. Nowadays, RBF is used for many situations such as for objective function approximation (Zhang et al. 2016). RBF can be used in mathematical form as given below:

$$
\hat{\mathrm{y}}_{\mathrm{RBF}}(\mathrm{X})=\sum_{\mathrm{i}=1}^{\mathrm{N}_{\text {tra }}} \mathrm{r}_{\mathrm{i}} \varnothing\left(\mathrm{X}-\mathrm{X}_{\mathrm{i}}\right)
$$

Where, $\hat{\mathrm{y}}_{\mathrm{RBF}}(\mathrm{X}) \mathrm{s}$ a metamodel function of RBF, $x_{i}$ is vector design variable at the training point, $\mathrm{X}-\mathrm{X}_{\mathrm{i}}$ is Euclidean distance, $r_{i}$ is the combination coefficient of $N_{\text {tra }}$ and $\varnothing$ the basic function.

Fang et al. (2005) used the RBF metamodel for the optimisation of various vehicle body objectives in a fatal crash, with verification using finite element simulation for the overall vehicle model. The results showed that RBF pro-duced a better model compared to RSM based on a similar number of reaction samples, with the identifiable multi-quadric function showing the most stable and more accurate RBF. Here, accident absorption capabilities were estimat-ed with RBF systems constructed using the minimum number of analysis elements. The surface response was coupled with genetic algorithms in order to produce a single constraint and optimisation of various objectives. The results proved that moderate eccentricity leads to a high-efficiency structure with stable front decay characteristics and good absorption ability having a mass reduction up to $7 \%$ with consideration of the impact of vertical impact and at least $20 \%$ for circular tubes (Lanzi et al. 2004).

In another study, Salehghaffari et al. (2011) examined the optimum design and value of the tubular tube. Metamodels were developed to determine the average energy absorption and destruction energy, using the RBF technique. Moreover, single design optimisation and a variety of objectives showed the optimum design for different reaction features. Xu et al. (2013) examined the vehicle structure subject to frontal impact. The main compo-nents of the vehicle front structure were selected as variables such as the structure thickness and vehicle weight using the RBF model. 


\subsubsection{Respons Surface Methods (RSM)}

The RSM method provides an effective way of constructing an approximate function for action using the highest level of linear, quadratic or polynomial equations. The commonly used RSM model employs linear and quadratic polynomials. For the real response function $\mathrm{f}^{\prime}(\mathrm{x})$, the RSM model uses quadratic polynomials as given below;

$$
f^{\prime}(x)=\beta_{o}+\sum_{i=1}^{n} \beta_{i} x_{i}+\sum_{i=1}^{n} \beta_{i i} x_{i}^{2}+\sum_{i=1}^{n-1} \sum_{j=i+1}^{n} \beta_{i j} x_{i} x_{j}
$$

where, $f^{\prime}(x)$ is the function of the surface reaction, $b_{0}$ is the constant coefficient, $x$ is variable of $-i$ and $-j$ from $n$ is the number of the design variable.

Baroutaji et al. (2015) used the RMS method with FEM to explore the effects of geometric parameters on oval tubes based on built-in models, and multi-objective optimisation from oval tube designs to achieve maximum SEA and minimum PCF. The side length and wall thickness were selected as the design variables. Both objectives and constraints were determined using the RSM method. Likewise, Hou et al. (2011) investigated the optimum shape for different ta-per tube configurations, (i.e. empty single-tap tube, foam-filled tapered tubes and double tapered tubes). The re-placement model method employing the RSM method was adopted in this study. In another study by Sheriff et al. (2008), they produced a mathematical model using the RSM method. Here, mathematical models were developed using experimental data and numerical data as an objective function for optimising the design. Mathematical models have also been used to predict absorbed energy and structural deformation.

\subsubsection{Artificial Neural Networks (ANN)}

ANNs is a mathematical model based on the principles inspired by the mind-set calculation (Gurney 1997) which can be used for complicated approximations between input and output data, described as metamodel methods. This method contains neurons, a small connected computing device (Simpson et al. 2004) which is a processing unit which usually has more than one input and produces only one output, as shown in Figure 10. Each input xi is the weight of wi, and the total input is calculated with a result. Then, the adaptation function is used as a result $(a)$ to provide output $f(a)$,

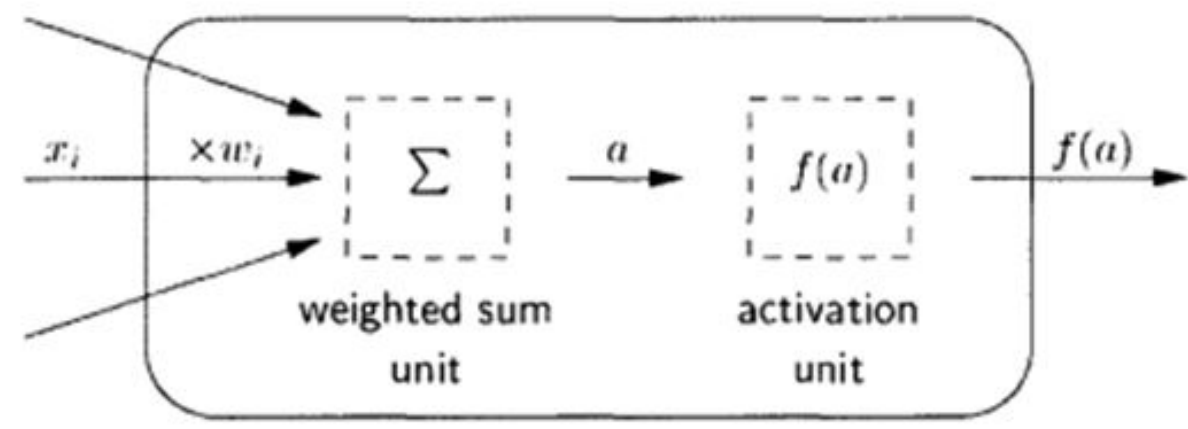

inputs

output

Figure 10: Schematic for a neuron device. Source: Ibrahim (2009).

Dai and Duan (2009) used ANNs to extract incoming/outgoing connections between the dynamic characteristics of accidents and the characteristics of the beam elements. Using this correlation, the characteristics of the beam elements were predicted by the dynamic characteristics of the expected crash. The analysis indicated that the beam element prediction model allowed the important features of the dynamic dynamics of the BIW concept to generate a design evaluation with a reasonable level of accuracy. The optimisation of various objective circular aluminium tubes has also been performed in different priority bases in order to create the ability for designers to select optimum dimension ratios.

Similarly, the crushing parameters for two aluminium alloys have also been compared (Marzbanrad and Ebrahimi 2011). Mirzaei et al. (2011) explored the optimisation of various objective cylindrical tube tubes under axial load impact. Here, the absorption energy and specific energy absorption were considered as an objective function, while the minimum 
load crushing could not exceed the permissible limits. The geometric dimensions of the tubes, including the diameter, length and thickness, were selected as the design variables.

\subsection{Optimisation Algorithms}

Several different algorithms can be employed to solve optimisation problems. The local optimisation algorithm is only used for locating local optimisation, as there is no guarantee of becoming a global optimisation technique unless certain requirements are met. Therefore, if the response has some local optimum, different results can be obtained depending on the starting point. Most local optimisation algorithms are based on gradients, i.e. they use gradient information to determine optimum solutions such as the studies conducted by Venter (2010). These techniques are popular given the efficiency of the results obtained, which can solve the problem having many design variables.

However, in the majority of cases, global optimisation is required because it has a better chance of determining or approaching optimum values globally. The global optimisation algorithm can be classified into two major categories; stochastic or heuristic algorithms (Younis and Dong 2010). The algorithms solve optimisation problems by generating determinative points that focus on optimal solutions globally. The stochastic algorithm is based on random point generation used for non-linear local optimisation search methods. Some phenomena inspire this algorithm, given it has a strong edge and is ideal for discrete optimisation problems. Compared to the algorithm of determination, this method usually has less restriction regarding mathematical features, can determine large design space and does not require gradient information. Whereas the algorithmic method of determination cannot guarantee that the optimal solution is found and requires more objective function evaluation. This stochastic optimisation algorithm is generally suited for optimising multiple objectives because the metamodel assessment does not require much time. Stochastic optimisa-tion algorithms include a genetic algorithm and swarm particle optimisation.

\subsubsection{Particle Swarm Optimisation (PSO)}

The swarm algorithm is based on the concept of swarm intelligence, and collective intelligence that originates from a group of individuals. This method is inspired by the behaviour of living organisms and interacts in large groups. One of the well-known algorithms is the optimisation of swarm particles that mimics birds. Accordingly, the swarm algorithm is a population-based algorithm such as an evolution algorithm. The swarm particle optimisation algorithm was intro-duced after examining the social behaviour of birds (Kennedy and Eberhart 1995). For example, searching for food, where each herd member specifies the velocity based on their personal experience as well as the information obtained through the interaction with other herd members. The same concept applies to the PSO, where the population is known as swarms, which convey the optimum information of each individual referred to as a particle and from which the information obtained is considered as a whole. The basic PSO algorithm has a reasonably simple formula to implement and modify and starts with a group of particles with randomly selected velocity and position in the design space. The particle's position is then updated from an iteration using a simple formula.

For instance, Gao et al. (2016b) utilised swarm particle optimisation algorithms for various objectives in estimating the optimum value of the double-filled double-tube ellipse with maximum SEA value and minimum PCF value under angular loading. Here, it was determined that the foam filled elliptical tubes had better crashworthiness performance (11.77\%) of the single foam elliptical tube and $10.51 \%$ better performance of the foam filled double-circular tube. Zhang et al. (2014) investigated empty cone tubes as well as containing full foam under different loading cases using multiobjective swarm particle optimisation algorithms. Here, it was found that the optimum value of cone tubes con-taining foam had better crashworthiness performance compared to empty cob tubes under oblique loading cases hav-ing four design variables, namely wall thickness, the upper end of the cone tube or taper angle, tube wall material pressure and foam density. In addition, the Pareto front method was identified in solving the optimisation problem of an objective range of empty and foam-shaped columns under axial and oblique loading using the swarm particle opti-misation algorithm by Yang et al. i (2013). Here, it was determined that the optimum value of column filled foam had better crashworthiness under pure axial load, but the optimum value for the empty column had better crashworthiness performance compared to the foam filled column tube under oblique effect. This case was due to the empty tubes having empty space in which to absorb more energy compared to the filled foam tube under oblique load.

\subsubsection{Genetic Algorthm (GA)}

In 1975, Holland developed a concept that described the principles of natural evolution for optimisation problems. The theory is based on genetic principles and evolution. Mathematical energy lies in the existence and method of a particu-lar model that describes many different phenomena and solves various problems. Genetic Algorithm (GA) and nondom-inated sorting genetic algorithm (NSGA) versions I and II are examples of evolutionary simulations that can solve 
opti-misation problems from various objectives. NSGA II has been used by many objective optimisations based on a fastpaced non-dominating arrangement. The non-master set can be obtained by using a non-mastered arrangement along with the elitisation of congestion distances. Fields are not mastered or acquired after each generation (Zheng et al. 2014). Finally, non-dominant sets are obtained with an iterative convergence to form the Pareto front.

Zhang et al. (2012) optimised the crashworthiness of double square columns with full foam using the kriging metamodel technique to formulate the objectives and functions of the constraints. Similarly, GA and NSGA II were used to obtain the optimal solutions to a single optimisation problem and a variety of objectives. Therefore, it is the conclusion of this present study that the optimised foam-filled double structure can provide better crashworthiness performance compared to single foam-filled tubes and double tubes. NSGA-II was also used to optimise cellular tubes for maximum SEA and reduce PCF. The five cell tubes were found to have better optimum crashworthiness values compared to cell and different topological configurations under dynamic effects conditions. Zheng et al. (2014) also compared the energy absorption characteristics of different polygon tubes to cross-sectional configuration across the NSGAII axis for maximum SEA values and minimum PCF values.

\subsection{Multi Objectives Optimisation for Stuctures}

To achieve the optimal configuration of foam or foam-filled cell material in a thin-walled room by providing enhanced crashworthiness, improvement in this field of study has been carried out in recent years. The use of optimisation tech-niques in structural design has also been used. For example, Zarei and Kroger (2008) examined the optimisation of various objectives for maximum energy absorption and reducing the weight of the tubes with full-loaded aluminium containers that were either axial or bending. Whereas, Yin et al. (2011) optimised single polygons and double tubes in order to achieve maximum SEA and minimum PCF. In another study, Hou et al. (2009) and Zhang et al. (2012) used a variety of objective optimisation methods for a single square and double-walled square head design with full foam filled aluminium material. Acar et al. (2011) also performed various objective crashworthiness optimisations from thin-walled circular taper tubes with coaxial symmetric ducts for maximum CFE and maximum SEAs. Sun et al. (2010) first used the swarm particle optimisation in crashworthiness designs based on a two-stage multi-loyalty method for a met-amodel.

Zarei and Kroger (2008) were early pioneers in the study of structural optimisation of foam-filled structures such as aluminium tubes with axial and bending impact tests. In their study, the results showed that foam-filled tubes had the same energy absorption value as compared to empty tubes but weighed $19 \%$ and $28.1 \%$ less. The optimisation method was further studied by Zhang et al. (2009) using a rib design by comparing empty square tube and with foam under bending loading. Here it was found that foam-filled tubes had the best energy absorption performance. For square tubes, Hou et al. (2009) developed a multi-objective optimisation design for a thin-walled column with foam-filled aluminium material. In their study, they examined the difference in the results between single objective optimisa-tion and various objectives. Similarly, another structure of single hexagonal tubes and three cells filled with foam was optimised for maximum specific energy with consideration of tubular thickness and foam density by Bi et al. (2010). Hou et al. (2011) and Acar et al. (2011) explored tapered circular tubes with different configurations. The tube configu-ration was empty single tapered, tapered foam and two inline tubes. Here, they found that the best structure was a double tube concentric having the best crashworthiness performance. As with the two concentric tubes, Zhang et al. (2012) examined the issue of thin-walled double structural designs filled with aluminium foams. While, Fang et al. (2014) explored the design of the circular double-blinded structure and Azarakhsh et al. (2015) examined double circular tubes with foam filled copper materials, subject to quasi-static axis loading. For different loading angles, Yang and Qi (2013) and Zhang et al. (2014) assessed the optimum value of crashworthiness of each structure, (i.e. square tube and foam filled foam cone) for variations in load angle, geometry and structural material. Whereas, Gao et al. (2016a) optimised single and double elliptical tubes containing foam with oblique effects. For all the studies mentioned above, there was limited information regarding double circular tube configurations under different loading angles.

For optimisation methods, metamodel techniques are widely used to reduce computing processing time. RBF as a metamodel technique demonstrates better accuracy for non-linear response approximations globally. Previous studies have also been successful in obtaining foam crashworthiness optimisation (Salehghaffari et al. 2011); Hou et al., 2009). The crashworthiness performance can also be examined using D-Optimal as an experimental design aimed at reducing the required number of samples (Myers and Montgomery 1995). For the metamodel method, good metamodel quality is produced (Redhe et al. 2002). Also, this experimental design method can minimise the cal-culation time. The genetic algorithm (GA) is a popular optimisation tool given it can prevent traps for optimising a sys-tem (Murugan et al. 2009). Likewise, the preparation of non-dominant genetic algorithms (NSGA) such as NSGA version I and II are considered to be more efficient and effective for solving, fitness and problem-solving status (Deb 2001). Tables 1 display some of the major research on optimising crashworthiness in thin-walled structures. 
Tables 1. Optimising design of crashworthiness for foam filled thin-walled structures.

\begin{tabular}{|c|c|c|c|c|c|}
\hline Researchers & Structures & $\begin{array}{l}\text { Loading } \\
\text { Condition }\end{array}$ & $\begin{array}{l}\text { Design of } \\
\text { Experiment }\end{array}$ & Meta model & Optimization \\
\hline $\begin{array}{l}\text { Zarei and Kroger } \\
\qquad(2008)\end{array}$ & $\begin{array}{l}\text { Square } \\
\text { columns }\end{array}$ & Bending /Dynamic & D-optimal & $\begin{array}{c}\text { Response } \\
\text { surface method }\end{array}$ & $\begin{array}{c}\text { Response } \\
\text { surface method }\end{array}$ \\
\hline $\begin{array}{l}\text { Zarei and Kroger } \\
\qquad(2008)\end{array}$ & Square tubes & Axial/Dynamic & D-optimal & $\begin{array}{c}\text { Response } \\
\text { surface method }\end{array}$ & $\begin{array}{c}\text { Response } \\
\text { surface method }\end{array}$ \\
\hline Hou et al. (2009) & $\begin{array}{l}\text { squared } \\
\text { columns }\end{array}$ & Axial/Dynamic & D-optimal & $\begin{array}{c}\text { Response } \\
\text { surface method }\end{array}$ & $\begin{array}{c}\text { Weighted } \\
\text { arithmetical } \\
\text { average method } \\
\text { Geometrical } \\
\text { average method }\end{array}$ \\
\hline Sun et al. (2010) & $\begin{array}{l}\text { squared } \\
\text { columns }\end{array}$ & Axial/Dynamic & $\begin{array}{l}\text { polynomial } \\
\text { functions }\end{array}$ & $\begin{array}{c}\text { response } \\
\text { surface method }\end{array}$ & $\begin{array}{c}\text { particle swarm } \\
\text { optimization }\end{array}$ \\
\hline Bi et al. (2010) & $\begin{array}{l}\text { Hexagonal } \\
\text { columns }\end{array}$ & Axial/Dynamic & $\begin{array}{l}\text { polynomial } \\
\text { functions }\end{array}$ & $\begin{array}{c}\text { Response } \\
\text { surface method }\end{array}$ & $\begin{array}{c}\text { Response } \\
\text { surface method }\end{array}$ \\
\hline Hou et al. (2011) & $\begin{array}{c}\text { Tapered } \\
\text { circular tubes }\end{array}$ & Axial/Dynamic & $\begin{array}{l}\text { Eactorial design } \\
\text { Latin } \\
\text { Hypercube } \\
\text { Sampling }\end{array}$ & $\begin{array}{c}\text { Response } \\
\text { surface method }\end{array}$ & $\begin{array}{c}\text { Particle swarm } \\
\text { optimization }\end{array}$ \\
\hline $\begin{array}{l}\text { Qi et al. (2012) } \\
\text { Zhang et al (2012) }\end{array}$ & $\begin{array}{c}\text { Tapered } \\
\text { square tubes } \\
\text { Double } \\
\text { square } \\
\text { column }\end{array}$ & $\begin{array}{c}\text { Oblique/Dynamic } \\
\text { Axial/Dynamic }\end{array}$ & $\begin{array}{l}\text { Full factorial } \\
\text { design } \\
\text { D-optimal }\end{array}$ & $\begin{array}{c}\text { Response } \\
\text { surface method } \\
\text { Kriging }\end{array}$ & $\begin{array}{c}\text { Particle swarm } \\
\text { optimization } \\
\text { Genetic } \\
\text { algorithm } \\
\text { Non-dominated } \\
\text { Sorting Genetic } \\
\text { Algorithm II }\end{array}$ \\
\hline Yang and Qi (2013) & $\begin{array}{l}\text { Square } \\
\text { columns }\end{array}$ & Oblique/Dynamic & D-optimal & Kriging & $\begin{array}{l}\text { Particle swarm } \\
\text { optimization }\end{array}$ \\
\hline Yin et al. (2013) & $\begin{array}{l}\text { Square } \\
\text { columns }\end{array}$ & Lateral/Dynamic & $\begin{array}{l}\text { Full factorial } \\
\text { design }\end{array}$ & $\begin{array}{l}\text { polynomial } \\
\text { functions }\end{array}$ & $\begin{array}{c}\text { multiobjective } \\
\text { particle swarm } \\
\text { optimization }\end{array}$ \\
\hline Yin et al. (2014a) & tapered tube & Axial/Dynamic & $\begin{array}{l}\text { Latin } \\
\text { Hypercube } \\
\text { Design }\end{array}$ & $\begin{array}{l}\text { polynomial } \\
\text { response } \\
\text { surface } \\
\text { radial basis } \\
\text { function } \\
\text { support vector } \\
\text { regression }\end{array}$ & $\begin{array}{l}\text { multiobjective } \\
\text { particle swarm } \\
\text { optimization }\end{array}$ \\
\hline Fang et al. (2014) & Square beam & $\begin{array}{l}\text { Lateral/Quasi- } \\
\text { static }\end{array}$ & $\begin{array}{l}\text { Latin } \\
\text { Hypercube } \\
\text { sampling }\end{array}$ & Kriging & $\begin{array}{c}\text { multiobjective } \\
\text { particle swarm } \\
\text { optimization }\end{array}$ \\
\hline Zheng et al. (2014) & $\begin{array}{c}\text { bitubal } \\
\text { polygonal } \\
\text { tubes }\end{array}$ & Axial/Dynamic & $\begin{array}{l}\text { Latin } \\
\text { Hypercube } \\
\text { sampling }\end{array}$ & $\begin{array}{l}\text { response } \\
\text { surface } \\
\text { radial basis } \\
\text { function } \\
\text { Kriging }\end{array}$ & $\begin{array}{c}\text { Non-dominated } \\
\text { Sorting Genetic } \\
\text { Algorithm II }\end{array}$ \\
\hline Li et al. (2014) & $\begin{array}{l}\text { Square } \\
\text { columns }\end{array}$ & Oblique/Dynamic & $\begin{array}{l}\text { Full factorial } \\
\text { design }\end{array}$ & $\begin{array}{l}\text { radial basis } \\
\text { function }\end{array}$ & $\begin{array}{c}\text { Non-dominated } \\
\text { Sorting Genetic } \\
\text { Algorithm II }\end{array}$ \\
\hline
\end{tabular}




\begin{tabular}{|c|c|c|c|c|c|}
\hline Researchers & Structures & $\begin{array}{l}\text { Loading } \\
\text { Condition }\end{array}$ & $\begin{array}{c}\text { Design of } \\
\text { Experiment }\end{array}$ & Meta model & Optimization \\
\hline Zhang et al. (2014) & conical tube & Oblique/Dynamic & D-optimal & Kriging model & $\begin{array}{c}\text { multiobjective } \\
\text { particle swarm } \\
\text { optimization }\end{array}$ \\
\hline Li et al. (2015) & $\begin{array}{l}\text { Square } \\
\text { columns }\end{array}$ & Lateral/Dynamic & $\begin{array}{l}\text { Latin } \\
\text { Hypercube } \\
\text { Sampling }\end{array}$ & Kriging model & $\begin{array}{c}\text { Non-dominated } \\
\text { Sorting Genetic } \\
\text { Algorithm II }\end{array}$ \\
\hline Hou et al. (2015) & $\begin{array}{l}\text { Square tube } \\
\text { Circular tube } \\
\text { Conical tube }\end{array}$ & Axial/Dynamic & $\begin{array}{l}\text { full factorial } \\
\text { design }\end{array}$ & $\begin{array}{c}\text { Response } \\
\text { Surface Method }\end{array}$ & $\begin{array}{c}\text { Sequential } \\
\text { quadratic } \\
\text { programming } \\
\text { Non-dominated } \\
\text { Sorting Genetic } \\
\text { Algorithm II }\end{array}$ \\
\hline $\begin{array}{l}\text { Djamaluddin et al. } \\
\qquad(2015 a)\end{array}$ & $\begin{array}{c}\text { Double } \\
\text { circular tube }\end{array}$ & $\begin{array}{c}\text { Axial and } \\
\text { Oblique/Dynamic }\end{array}$ & D-optimal & $\begin{array}{l}\text { radial basis } \\
\text { function }\end{array}$ & $\begin{array}{c}\text { Non-dominated } \\
\text { Sorting Genetic } \\
\text { Algorithm II }\end{array}$ \\
\hline $\begin{array}{l}\text { Djamaluddin et al. } \\
\qquad(2015 b)\end{array}$ & $\begin{array}{c}\text { Double } \\
\text { circular tube }\end{array}$ & $\begin{array}{l}\text { Axial/Quasi-static } \\
\text { and Dynamic }\end{array}$ & D-optimal & $\begin{array}{l}\text { radial basis } \\
\text { function }\end{array}$ & $\begin{array}{c}\text { Non-dominated } \\
\text { Sorting Genetic } \\
\text { Algorithm II }\end{array}$ \\
\hline Gao et al. (2016a) & $\begin{array}{l}\text { Double } \\
\text { ellipse tube }\end{array}$ & $\begin{array}{c}\text { Axial and } \\
\text { Oblique/Dynamic }\end{array}$ & D-optimal & Kriging & $\begin{array}{c}\text { multiobjective } \\
\text { particle swarm } \\
\text { Optimization }\end{array}$ \\
\hline Gao et al. (2016b) & ellipse tubes & Oblique/Dynamic & D-optimal & $\begin{array}{c}\text { Quartic } \\
\text { polynomial } \\
\text { functions }\end{array}$ & $\begin{array}{c}\text { Non-dominated } \\
\text { Sorting Genetic } \\
\text { Algorithm II }\end{array}$ \\
\hline Yin et al. (2017) & $\begin{array}{l}\text { Tapered } \\
\text { multi cell } \\
\text { tube }\end{array}$ & $\begin{array}{l}\text { Bending and } \\
\text { Quasi static }\end{array}$ & Full Factorial & $\begin{array}{l}\text { radial basis } \\
\text { function }\end{array}$ & $\begin{array}{c}\text { Non-dominated } \\
\text { Sorting Genetic } \\
\text { Algorithm II }\end{array}$ \\
\hline Ying et al. (2017) & Tapered tube & Oblique/Dynamic & Full Factorial & $\begin{array}{l}\text { radial basis } \\
\text { function }\end{array}$ & $\begin{array}{c}\text { Non-dominated } \\
\text { Sorting Genetic } \\
\text { Algorithm II }\end{array}$ \\
\hline
\end{tabular}

Zhang et al. (2012) investigated the crashworthiness design of foam filled double-ended tube. Various optimi-sation objectives indicated that the foam-filled double structure had better crashworthiness compared to a single foam-filled structure. Figure 11 shows the deformation using experimental and simulation methods. Fang et al. (2014) used Multiobjective Robust Design Optimisation (MORDO) to study the design of the double-bedded structure where the results showed that the proposed method could improve the reliability of Pareto's solution. Zheng et al. (2014) later compared the energy absorption characteristics of single and double-filled polygon tubes with different cross-section configurations under axial loading. The results revealed that the filled double circular tubes had a superior energy absorption feature. It was also shown that the minimum absorption and absorption energy generally increased with the increase of the number of edges of the double-column foam. 


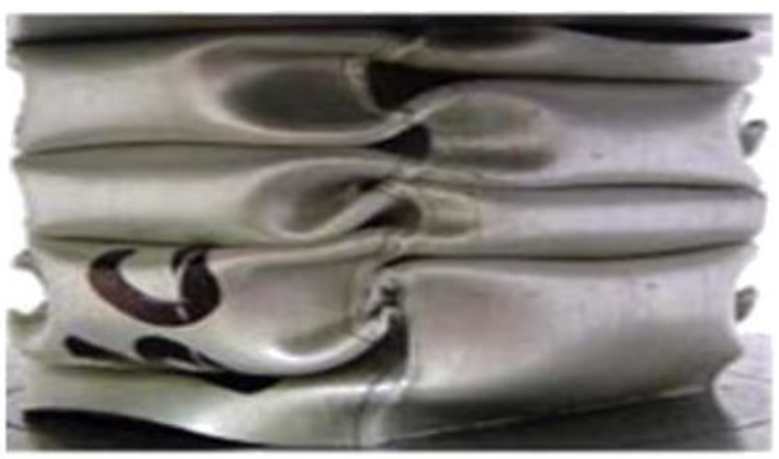

(a)

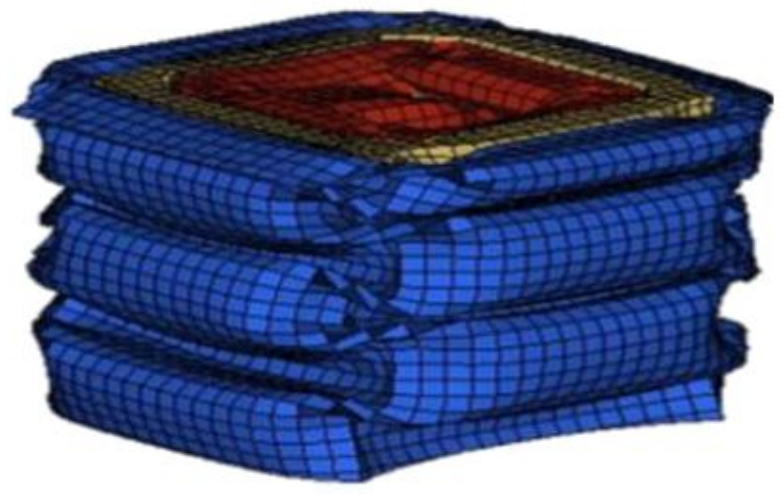

(b)

Figure 11: Deformation modes of double foam filled tubes for (a) experiment, and (b) simulation. Source: Zhang et al. (2012).

In the field of automotive engineering, the bumper system requires a defensive load of up to $30^{\circ}$ longitudinally from the axial loading (Reyes et al. 2002). In this case, thin-walled structures continually undergo flexible bending and axial deformation versus pure bending collisions designed as effective deformation modes for energy ab-sorption. Yang and Qi (2013) developed an optimisation procedure for a blank square head design and full foam rub-bers under oblique loading. The results showed that coupling with foam-filled tubes, the empty space may have better buoyancy through the burden of oblique effects compared to pure axial loading. Also, Qi et al. (2012) examined the comfort design for cone tubes, as shown in Figure 12.

Further, multiple cell tube studies have considered oblique loads, such as the work of Qi et al. (2012) using LS-DYNA to predict the behaviour of rectangular tube arrangements with different cells subjected to oblique loads. Here they found that tapered tubes with multiple cells had the best fluency performance. While Song and Guo (2013); Djamaluddin et al. (2015c, 2016); found that the effectiveness of multi-cell configuration could increase energy absorption by increasing the load angle and multi-cell tubes which could also worsen performance if the structure collapsed in a pure global bending mode. Fang et al. (2015) investigated multiple cell tubes having different cell numbers comprehensively under both axial and oblique loads where the results indicated that the load angle for different cells had lower crashworthiness performance compared to single cells.

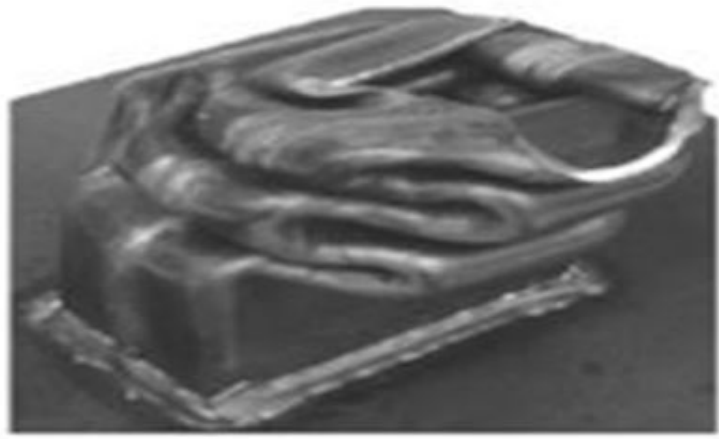

(a)

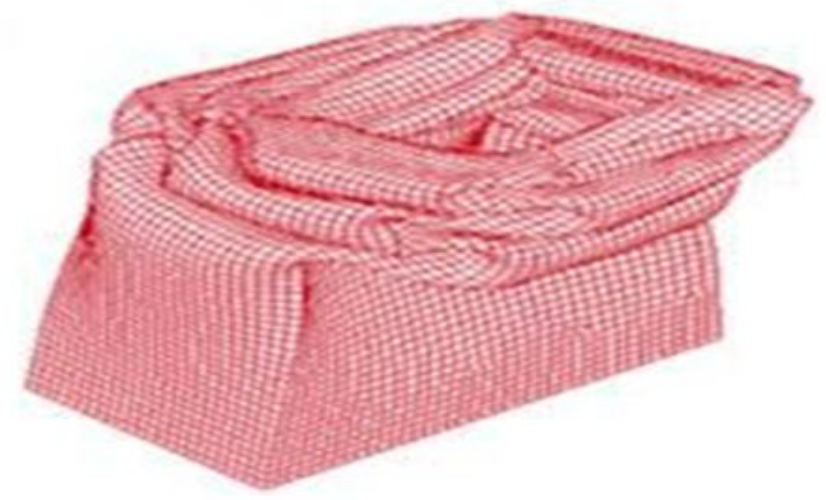

(b)

Figure 12: Deformation modes of the tapered tube under oblique load; (a) experiment and (a) simulation. Source: Qi et al. (2012).

\section{CONCLUSION}

This paper contains important research references such as structural crashworthiness, the collapse of energy absorp-tion structure, thin-walled foam structure, foam mechanical properties, collapse modes for thin-walled structures, finite element models for energy-absorbers, optimisation concepts, optimisation algorithms, metamodel development, metamodel verification, and the crashworthiness optimisation method for foam-filled thin-walled 
structures. It has been shown in this paper, that foam as a fused-walled filler material helps improve the stability of collapse occurring. Further, the aluminium foil filled structure can increase the energy absorption force due to the interaction between the tube and the filler foam. The types of foam-filled tubes with different cross-sections such as circular tubes, square tubes, caps shaped tubes, rectangular tapered tubes and cone tubes were examined and compared. The cell profile arrangement was used with the same cross-section as foam filled double tube in order to increase the crashworthiness parameter value. It was shown that the combination of angular loading directions would affect real vehicles more often in the event of a collision.

\section{Editor: Marcílio Alves.}

\section{References}

Abedi, M.M., Niknejad, A., Liaghat, G.H., \& Nejad, M.Z. (2012). Theoretical and experimental study on empty and foam-filled columns with square and rectangular cross section under axial compression. International Journal of Mechanical Sciences 65 : 134-146.

Acar, E., Guler M.A., Gerçeker, B., Cerit, M.E., \& Bayram, B. 2011. Multi-objective crashworthiness optimization of tapered thin-walled tubes with axisymmetric indentations. Thin-Walled Structures 49: 94-105.

Ahmad, Z. \& Thambiratnam, D.P. 2009. Dynamic computer simulation and energy absorption of foam-filled conical tubes under axial impact loading. Computers and Structures 87(3-4): 186-197.

Ahmad, Z., Thambiratnam D.P. \& Tan A.C.C. 2010. Dynamic energy absorption characteristics of foam-filled conical tubes under oblique impact loading. International Journal of Impact Engineering 37: 475-488

Alghamdi, A.A.A. 2001. Collapsible impact energy absorbers: An overview. Thin-Walled Structures 39(2): $189-213$.

Allahbakhsh, H.R. \& Saetni J. 2011. Design optimization of square and circular alumi- nium extrusion damage columns with crashworthiness criteria. Indian Journal Engineering Materials Sciences 18(5): 341-350

Altenhof, W., Harte, A.M. \& Turchi, R. 2002. Experimental and numerical compressive testing of aluminium foam-filled mild steel tubular hat sections. 7th International LS-DYNA Users Conference, May, 21-24, 2002 Ontario, Canada.

Azarakhsh, A., Rahi, A., Ghamarian, H. \& Motamedi, T. 2015. Axial crushing analysis of empty and foam-filled brass bitubular cylinder tubes, Thin-Walled Structures 95: 60-72.

Baroutaji, A., Gilchrist, M.D., Smyth, D. \& Olabi A.G. 2015. Crush analysis and multi-objective optimization design for circular tube under quasi-static lateral loading. Thin-Walled Structures 86: 121-131.

Bi, J., Fang, H., Wang, Q. \& Ren X. 2010. Modeling and optimization of foam-filled thin-walled columns for crashworthiness designs. Finite Elements in Analysis and Design 46: 698-709.

Borvik, T., Hopperstad, O.S., Reyes, A., Langseth, M., Solomos, G. \& Dyngeland, T. 2003. Empty and foam-filled circular aluminium tubes subjected to axial and oblique quasi static loading. International Journal of Crashworthiness 8(5): $481-494$.

Dai, Y. \& Duan, C. 2009. Beam element modelling of vehicle body-in-white applying artificial neural network. Applied Mathematical Modelling 33: 2808-2817.

Deb, K. 2001. Multiobjective Optimization Using Evolutionary Algorithms. New York: John Wiley \& Sons.

Djamaluddin F, Abdullah S, Ariffin AK, Nopiah, Z.M 2015a. Optimization of foam-filled double circular tubes under axial and oblique impact loading conditions. Thin Walled Structure. 87:1-11.

Djamaluddin F, Abdullah S, Ariffin, AK Nopiah, Z.M 2015b. Multi objective optimization of foam-filled tubular circular tubes for quasi static and dynamic responses Latin American Journal of Solids and Structures . 12:1126-1143

Djamaluddin, F., Abdullah, S., Arrifin, A.K., Nopiah, Z.M, 2015c, Modeling and optimization of aluminum foam cylindrical double tubes under axial impact. Journal of Mechanical Engineering and Sciences

Djamaluddin, F., Abdullah, S., Arrifin, A.K., Nopiah, Z.M 2016 Finite element analysis and crashworthiness optimization of foam-filled double circular under oblique loading. Latin American Journal of Solids and Structures 
Fang, H., Rais-Rohani, M. Liu, Z. \& Horstemeyer M.F. 2005. A comparative study of metamodeling methods for multiobjective crashworthiness optimization. Computers and Structures 85: 2121-2136.

Fang, J., Gao, Y., Sun, G., Qiu, N. \& Li, Q. 2015. On design of multi-cell tubes under axial and oblique impact loads. Thin-Walled Struc-tures 95: 115-126.

Fang, J., Gao, Y., Sun, G., Zhang, Y. \& Li, Q. 2014. Crashworthiness design of foam-filled bitubal structures with uncertainty. Interna-tional Journal of Non-linear Mechanics 65: 113-124.

Gao, Q., Wang, L., Wang, Y. \& Wang, C. 2016a. Crushing analysis and multiobjective crashworthiness optimization of foamfilled ellipse tubes under oblique impact loading. Thin-Walled Structures 100: 105-112.

Gao, Q., Wang, L., Wang, Y., Wang, C. \& Zhang, Z. 2016b. Optimization of foam-filled double ellipse tubes under multiple loading cases. Advances in Engineering Software 99: 27-35

Ghamarian, H.R. Zarei, M.T. \& Abadi, 2011. Experimental and numerical crashworthiness investigation of empty and foamfilled end- capped conical tubes, Thin-Walled Structures 49: 1312-1319.

Gunn, S. 1998. Support Vector Machine for Classification and Regression. Tesis Doktor Falsafah, University of Southampton.

Guo, L.W. \& Yu, J.L. 2010. Bending response of sandwiched double tube structures with aluminum foam core. Proceedings of the ISCM II \& EPMESC XII, November, 30 - December, 3, 2009, Hong Kong.

Guo, L.W. \& Yu, J.L. 2011. Dynamic bending response of double cylindrical tubes filled with aluminum foam. International Journal Impact Engineering 38: 85-94.

Gurney, K. 1997. An Introduction to Neural Networks. London: CRC Press.

Han, D.C. \& Park, S.H. 1999. Collapse behavior of square thin-walled columns subjected to oblique loads. Thin-Walled Structures 35(3): 167-184.

Hanssen, A.G., Langseth, M. \& Hopperstad, O.S. 2000. Static and dynamic crushing of square aluminium extrusions with aluminium foam filler. International Journal of Impact Engineering 24: 347-383.

Hou, S.J., Li, Q., Long, S.Y., Yang, X. \& Li, W. 2009. Crashworthiness design for foam filled thin-wall structures. Materials and Design 30(6): 2024-2032.

Hou, S., Han, X., Sun, G., Long, S., Li, W., Yang, X. \& Li Q. 2011. Multiobjective optimization for tapered circular tubes. ThinWalled Structures 49: 855-863.

Hou, S., Zhao, S. Rena, L., Han, X. \& Li, Q. 2013. Crashworthiness optimization of corrugated sandwich panels. Materials and Design 51: 1071-1084.

Hou, S., Liu, T., Zhang, Z., Han, X \& Li, Q. 2015. How does negative Poisson's ratio of foam filler affect crashworthiness? Materials and Design 82: 247-259

Ibrahim, H. K. 2009. Design Optimzation of Vehicle Structure for Crashworthiness Improvement. PhD Thesis, Concordian University.

Kavi, H., Tasoy, A.K. \& Guden, M. 2006. Predicting energy absorption in a foam-filled thin-walled aluminum tube based on experimentally determined strengthening coefficient. Materials and Design 27(4): 263-269.

Kennedy, L. \& Eberhart, R. C. 1995. Particle swarm optimization. Proceedings of IV IEEE Conference On Neural Networks, March, 14-16, 1995, New Jersey.

Kim H.S. 2002. New extruded multi-cell aluminum profile for maximum crash energy absorption and weight efficiency. ThinWalled Structures 40: 311-327.

Lanzi, L., Castelletti, L.M.L. \& Anghileri, M. 2004. Multi-objective optimization of composite absorber shape under crashworthiness requirements. Composite Structures 65(3-4): 433-441.

Li, F., Sun, G., Huang, X., Rong, J. \& Li, Q. 2015. Multiobjective robust optimization for crashworthiness design of foam filled thin-walled structures with random and interval uncertainties. Engineering Structures 88: 111-124 .

Li, G., Zhang, Z., Sun, G., Xu, F. \& Huang, X. 2014. Crushing analysis and multiobjective optimization for functionally graded foam- filled tubes under multiple load cases. International Journal of Mechanical Sciences 89: 439-452 
Marzbanrad, J \& Ebrahimi, M.R. 2011. Multi-Objective Optimization of aluminum hollow tubes for vehicle crash energy absorption using a genetic algorithm and neural networks. Thin-Walled Structures 49: 1605-1615.

Marzbanrad, J., Alijanpour, M. \& Kiasat M.S. 2009. Design and analysis of an automotive bumper beam in low-speed frontal crashes.Thin-Walled Structures 47: 902-911.

Mirfendereski, L., Salimi, M. \& Ziaei-Rad, S. 2008. Parametric study and numerical analysis of empty and foam-filled thinwalled tubes under static and dynamic loadings. International Journal of Mechanical Sciences 50(6): 1042-1057.

Mirzaei, M., Shakeri, M., Sadighi, M. \& Akbarshahi. 2011. Crashworthiness Design for Cylindrical Tube using Neural Network and Ge-netic Algorithm. Procedia Engineering 3346-3353.

Murugan, P., Kannan, S. \& Baskarb, S. 2009. NSGA-II algorithm for multi-objective generation expansion planning problem. Electric Power Systems Research 79: 622-628.

Myers, R.H. \& Montgomery, D.C. 1995. Response Surface Methodology: Process and Product Optimization using Designed Experi-ments. New York: Wiley Press.

Nagel, G.M. \& Thambiratnam, D.P. 2004. Dynamic simulation and energy absorption of tapered tubes under impact loading. Inter-national Journal of Crashworthiness 9(4): 389-399.

Nagel, G.M. \& Thambiratnam, D.P. 2006. Dynamic simulation and energy absorption of tapered thin-walled tubes under oblique im-pact loading. International Journal of Impact Engineering 32(10): 1595-1620.

Pan, F, Zhu, P. \& Zhang, Y. 2010. Metamodel-based lightweight design of B-pillar with TWB structure via support vector regression. Computers and Structures 88: 36-44.

Qi, C., Yang, S. \& Dong, F. 2012. Crushing analysis and multiobjective crashworthiness optimization of tapered square tubes under oblique impact loading, Thin-Walled Structures 59: 103-119.

Rajasekaran, S., Gayathri, S. \& Lee T.L. 2008. Support vector regression methodology for storm surge predictions. Ocean Engineering 35(16): 1578-1587.

Ravindran, A., Rekalitis, G.V. \& Ragsdell, K.M. 2006. Engineering Optimization: Methods and Applications. New York: John Wiley \& Sons.

Redhe, M., Forsberge, J., Janssone, T., Marklund P.O. \& Nilsson, L. 2002. Using the response surface methodology and the Doptimality criterion in crashworthiness related problems an analysis of the surface approximation error versus the number of function evaluations. Structural and Multidisciplinary Optimization 24: 185-194.

Reyes, A., Langseth, M. \& Hopperstad, O.S. 2002. Crashworthiness of aluminum extrusions subjected to oblique loading: experiments and numerical analyses. International Journal of Mechanical Sciences 44(9): 1965-1984.

Reyes, A., Langseth, M. \& Hopperstad, O.S. 2003. Square aluminum tubes subjected to oblique loading. International Journal of Im-pact Engineering 28(10): 1077-1106.

Ryberg, B. 2013. Metamodel-Based Design Optimization - A Multidisciplinary Approach for Automotive Structures. Tesis Doktor Falsafah, Linköping University, Sweden.

Santosa, S., Wierzbicki, T., Hanssen, A.G. \& Langseth, M. 2000. Experimental and numerical studies of foam-filled sections. Interna-tional Journal of Impact Engineering. 24(5): 509-534.

Salehghaffari, S., Rais-Rohani, M., \& Anajafi. 2011 Analysis and optimization of externally stiffened crush tubes. Thin-Walled Structures 49: 397-408.

Seitzberger, M. \& Willminger, S. 2001. Application of plastic collapse mechanisms for the axial crushing analysis of tubular steel struc-tures filled with aluminium foam. International Journal of Crashworthiness 6(2): 165-176.

Sheriff, N.M., Gupta, N.K., Velmurugan, R. \& Shanmugapriyan, N. 2008. Optimization of thin conical frusta for impact energy absorp-tion. Thin-Walled Structures 46(6): 653-666.

Simpson, T., Booker, A., Ghosh, D., Giunta, A., Koch, P. \& Yang, R. 2004. Approximation methods in multidisciplinary analysis and optimization: a panel discussion. Structural and Multidisciplinary Optimization 2: 302-313.

Song, H.W., Fan, Z.H., Yu, G., Wang, Q.C. \& Tobota, A. 2005. Partition energy absorption of axially crushed aluminum foamfilled hat sections. International Journal of Solids and Structures 42(9-10): 2575-2600. 
Song, J. \& Guo, F. 2013. A comparative study on the windowed and multi-cell square tubes under axial and oblique loading. Thin-Walled Structures 66: 9-14.

Sun, G.Y., Li, G.Y., Hou, S.J., Zhou, S.W., Li, W., Li, Q. 2010. Crashworthiness design for functionally graded foam filled thinwalled structures. Material Science Engineering 527: 1911-1919.

Tarlochan, F., Samer, F., Hamouda, A.M.S., Ramesh, S., Karam, K. 2013. Design of thin wall structures for energy absorption applications: Enhancement of crashworthiness due to axial and oblique impact forces. Thin-Walled Structures 71: 7-17.

Toksoy, A.K. \& Guden, M. 2005. The strengthening effect of polystyrene foam filling in aluminum thin-walled cylindrical tubes. Thin-Walled Structures 43(2): 333-350.

Venter, G. 2010. Review of Optimization Techniques. Encyclopedia of Aerospace Engineering. Chichester: John Wiley \& Sons Press.

Wang, Q., Fan, Z. \& Gui, L. 2007. Theoretical analysis for axial crushing behaviour of aluminium foam-filled hat sections. International Journal Mechanical Sciences 5(3): 515-521

Xu, F., ·Sun, G., ·Li, G. \& ·Li, Q. 2013. Crashworthiness design of multi-component tailor-welded blank (TWB) structures. Structural and Multidisciplinary Optimization 158-167.

Yan, W.Y., Durif, E., Yamada, Y. \& Wen, C. 2007. Crushing simulation of foam- filled aluminium tubes. Materials Transactions 48(7): 1901-1906.

Yang, S. \& Qi, C. 2013. Multiobjective optimization for empty and foam-filled square columns under oblique impact loading. Interna-tional Journal Impact Engineering 54: 177-191.

Yin, H., Wen, G., Hou, S. \& Chen, K. 2011. Crushing analysis and multiobjective crashworthiness optimization of honeycombfilled single and bitubular polygonal tubes. Materials and Design 32: 4449-4460.

Yin, H., Wen, G., Hou, S. \& Qing, Q. 2013. Multiobjective crashworthiness optimization of functionally lateral graded foamfilled tubes. Materials and Design 44: 414-428

Yin, H., Wen, G., Liu, Z. \& Qing, Q. 2014a. Crashworthiness optimization design for foam-filled multi-cell thin-walled structures. Thin-Walled Structures 75: 8-17.

Yin, H., Wen, G., Fang, H., Qing, Q., Kong, X., Xiao, J. \& Liu, Z. 2014b. Multiobjective crashworthiness optimization design of functionally graded foam-filled tapered tube based on dynamic ensemble metamodel. Materials and Design 55: $747-757$.

Yin, H., Chen, C., Huc, T. \& Wen, G. 2017. Optimisation for bending crashworthiness of functionally graded foam-filled cellular structure. International Journal of Crashworthiness 34: 212-227.

Ying, L., Dai, M., Zhang, S., Ma, H. \& Hu, P. 2017. Multiobjective crashworthiness optimization of thin-walled structures with functionally graded strength under oblique impact loading. Thin-Walled Structures 117: 165-177.

Younis, A. \& Dong, Z. 2010. Trends, features, and tests of common and recently introduced global optimization methods. Engineering Optimization 42(8): 691-718.

Yuen, S.C.K., Nurick, G.N. \& Starke, R.A. 2008. The energy absorption characteristics of double-cell tubular profiles. Latin American Journal of Solids and Structures 5(4): 289-317.

Zarei, H.R. \& Kroger, M. 2007. Crashworthiness optimization of empty and filled aluminum crash boxes. International Journal of Crashworthiness 12(3): 255-264.

Zarei, H.R. \& Kroger, M. 2008. Optimization of the foam-filled aluminum tubes for crush box application. Thin-Walled Structures 46(2): 214-221.

Zhang, X., Zhang, H. \& Wang, Z. 2016 Bending collapse of square tubes with variable thickness. International Journal of Mechanical Sciences 106: 107-116.

Zhang, X.W., Tian, Q.D. \& Yu, T.X. 2009. Axial crushing of circular tubes with buckling initiators. Thin-Walled Structures 47(6-7): 788-797.

Zhang, Y., Sun, G., Li, G., Luo, Z. \& Li, Q. 2012 Optimization of foam-filled bitubal structures for crashworthiness criteria. Materials and Design 38: 99-109. 
Zhang, Y., Sun, G., Xu, X., Li, G. \& Li, Q. 2014. Multiobjective crashworthiness optimization of hollow and conical tubes for multiple load cases. Thin-Walled Structures 82: 331-342.

Zheng, G., Wu, S., Sun, G., Li, G. \& Li, Q. 2014. Crushing analysis of foam-filled single and bitubal polygonal thin-walled tubes. Inter-national Journal of Mechanical Sciences 87: 226-240.

Zhu, P., Pan, F., Chen, W. \& Zhang, S. 2012. Use of support vector regression in structural optimization: application to vehicle crashworthiness design. Mathematics and Computers in Simulation 86: 21-31. 